\title{
Every Member of Your Team is a Salesperson
}

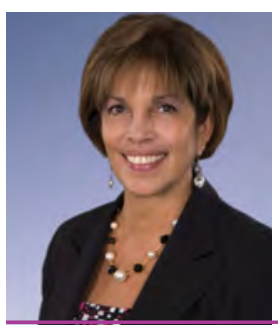

Pauline Blachford consults with optometrists across North America on how to reduce unbooked appointments, increase eyewear sales, and improve employee engagement and productivity. She coaches optometric staff on strategies and techniques for effectively recalling patients, and has developed a workshop designed to empower employees with the tools to contribute valuably to their clinic. Pauline writes regularly about practice management for the Canadian Journal of Optometry and is frequently invited to speak at industry conferences and events across the continent. For more information or to connect, visit www.paulineblachford.com.

I n my two decades working on the business side of this industry, I've seen how it can be a challenge for small, independent optometry practices to employ a full-time optician to oversee eyewear sales. Even at larger practices where there may be several opticians, it can be a struggle to significantly increase sales without a proper strategy in place. Whether a practice's budget, staff and resources are small or great, the most cost-effective, productive and successful way to boost eyewear sales is to convert your entire optometry team into a team of capable, confident salespeople.

At any practice, the OD, optician, recallers and front-desk staff have the eye health, eye care or patient expertise to effectively ensure a patient's eye care needs are met. That knowledge can also be applied to make eyewear sales a team initiative that leverages staff insight and utilizes existing resources, all while prioritizing patient needs and boosting the practice's bottom line.

There is a learning curve inherent to implementing a strong sales strategy in any industry: finding the time to sell, personalizing sales pitches, communicating value, and ensuring efficiency are challenges that will need to be overcome. ${ }^{1}$ However, the prospect of increased eyewear sales and greater revenue should be worth the time, patience and effort. Here are three ways to begin turning your existing optometry team into an effective and profitable team of sales staff.

\section{ENSURE EVERYONE AT YOUR PRACTICE KNOWS YOUR EYEWEAR PRODUCTS}

Whether it's types of frames, prices, colours or warranty, the more information your staff members have about the products you sell, the more likely they will be able to sell them. ${ }^{2}$

Your recallers or front-desk staff do not need to become experts, but they should have access to product information - and be given time to learn it - so that they can answer patient questions, and identify, respond to and note patient eyewear needs while booking appointments or chatting with patients in the waiting room. Having more informed employees also means that during vacations, illness or turnover, your practice's eyewear sales strategy doesn't get put on hold.

Encourage employees to spend time familiarizing themselves with your practice's products. Bringing in sales representatives to speak to your full team, reviewing testimonials, reading market literature and physically looking at and using some of the products you have in stock are good ways to get started on expanding your team's knowledge. ${ }^{3}$

\section{GET YOUR TEAM LEVERAGING EACH AND EVERY OPPORTUNITY}

Every time a patient calls, emails or enters your practice, it's an opportunity to have a positive impact that could lead to a sale. ${ }^{4}$ While booking an appointment over the phone, a recaller should feel empowered to ask a patient about their current eyewear, their eyewear needs and contact lens refills, as appropriate. He or she should also remind patients to bring in their existing glasses.

Selling a product like eyewear is easier with visuals. Eyewear should be attractively displayed in an area - such as the waiting room - that makes it easy for patients to browse at their leisure. You can also have your staff wear products that are sold at your practice - a promotional opportunity that can easily be included as an employee benefit. ${ }^{5}$ 
Finally, an OD should discuss eyewear with the patient during their eye health exam, and personally introduce them to the practice's optician for further questions. This helps transfer patient-doctor trust to other members of the optometry team.

\section{LISTEN ACTIVELY, TAKE NOTES AND SHARE YOUR FEEDBACK WITH THE TEAM}

Thinking like a strategic salesperson means thinking about how you can better help and serve your customers. To do so effectively means to first collect as much information as possible: Are your patients on a budget? Do they have insurance plans that include funds for eyewear? Have they expressed concerns about their current products?

Have your staff ask open-ended questions, and engage patients in conversations about their needs, concerns and thoughts. ${ }^{6}$ Any time new information is learned, have a process for adding that to a patient's file in such a way that it can be accessed by all team members. Another way to do this is to have a recaller let the OD and optician know that a patient will be bringing in their eyewear, and are interested in looking at new products. This ensures the entire team is prepared to discuss eyewear options as soon as the patient visits.

\section{NEXT STEPS}

Investment in staff is one of the most important factors of all when it comes to ensuring the success of your budding sales team. ${ }^{7}$ Hiring a sales professional to train your staff on how to communicate value, actively listen to patient needs, and close a sale could help get your team's skill level to the next level.

Keep sales top-of-mind in meetings, and encourage regular conversations about products, sales and experiences. You may have a staff member with past experience in retail who can share their knowledge with their colleagues. Regular check-ins with your team also provide a forum where questions, insights and experiences can be shared and discussed, to the benefit of the entire team.

Finally, setting a clear goal for increasing your eyewear sales and tracking your progress is a critical. Only $28 \%$ of organizations that prepare progress reports actually use the data they collect to improve their training for sales representatives. ${ }^{8}$ Sharing eyewear sales information and patient feedback, and using it to improve your strategy, will empower your team to effectively achieve your eyewear sales goals, while giving your practice a competitive edge when it comes to sales.

\section{REFERENCES}

1 Faust C. "The Three Biggest Challenges of Today's Sales Reps", MarketingProfs, May 26, 2015. Retrieved from http://www.marketingprofs.com/opinions/2015/27725/the-three-biggest-challengesof-todays-sales-reps

2 Connick W. "How to Sell Any Product", The Balance, September 30, 2016. Retrieved from https://www.thebalance.com/how-to-sellany-product-2917619

3 Hudson M. "The Benefits of Product Knowledge", The Balance, February 1, 2017. Retrieved from https://www.thebalance.com/ benefits-of-product-knowledge-2890302

4 Downes M. "Everybody's a salesperson", Financial Times, October 5, 2012. Retrieved from: https://www.ft.com/ content/6aeb63c0-e535-11el-8ac0-00144feab49a
5 "Five Points of Selling High-End Eyewear by Optylux", The Optical Vision Site, June 24, 2009. Retrieved from: http://www.theopticalvisionsite.com/sales/five-points-of-selling-high-end-eyewearby-optylux/

6 Parinello T. "How to Sell in 60 Seconds", Entrepreneur. Retrieved from: https://www.entrepreneur.com/article/65972

7 Downes M. "Everybody's a salesperson", Financial Times, October 5, 2012. Retrieved from: https://www.ft.com/ content/6aeb63c0-e535-11el-8ac0-00144feab49a

8 Faust C. "The Three Biggest Challenges of Today's Sales Reps", MarketingProfs, May 26, 2015. Retrieved from http://www.marketingprofs.com/opinions/2015/27725/the-three-biggest-challengesof-todays-sales-reps 